\title{
Remarkable variability in renal disease in a large Slovenian family with Fabry disease
}

\author{
Franc Verovnik ${ }^{\star}, 1$, Davorin Benko ${ }^{1}$, Bojan Vujkovac ${ }^{1}$ and Gabor E Linthorst ${ }^{2}$ \\ ${ }^{1}$ Department of Internal Medicine, General Hospital Slovenj Gradec, Slovenj Gradec, Slovenia; ${ }^{2}$ Departments of Internal \\ Medicine and Clinical Haematology, Academic Medical Center, Amsterdam, The Netherlands
}

Following the diagnosis of Fabry disease in a 45-year-old male, in 31 family members $\alpha$-galactosidase A ( $\alpha$-Gal) activity in leucocytes was measured and mutation analysis of the $\alpha$-Gal gene was performed. In the proband, the unique mutation A10523G/N272S in exon 6 was found, which was subsequently detected in seven males (of which one twin) and 10 female subjects. All males showed decreased to absent $\alpha$-Gal A activity in leucocytes, but three out of 10 female subjects had $\alpha$-Gal A activities within normal range. Although all male patients had symptoms of classical Fabry disease, such as acroparesthesias, hypohydrosis and heat-intolerance, there was considerable variability in organ involvement, especially in deterioration of renal function. Detailed studies of large families with Fabry disease may give insight into factors that influence the phenotype of this disorder.

European Journal of Human Genetics (2004) 12, 678-681. doi:10.1038/sj.ejhg.5201184

Published online 26 May 2004

Keywords: Fabry disease; $\alpha$-galactosidase A enzyme; mutation; genotype-phenoptype correlation

\section{Introduction}

Fabry disease (MIM 301500) is an X-linked genetic disorder of glycosphingolipid catabolism, resulting from the deficient activity of the lysosomal hydrolase, $\alpha$-galactosidase $\mathrm{A}$ (E. C.3.2.1.22; $\alpha$-Gal A). ${ }^{1}$ In this disorder, the enzyme defect leads to the pathologic accumulation of neutral glycosphingolipids with terminal $\alpha$-galactosyl residues in lysosomes of the vascular endothelium and smooth muscle cells in various organs. In childhood and adolescence, male patients develop acroparesthesias, angiokeratoma, hypohydrosis and corneal deposits (cornea verticillata). With advancing age, progressive endothelial involvement results in cardiac hypertrophy, renal failure, and strokes, leading to premature death. Some patients only exhibit complications in a single organ such as the heart or the kidney, referred to as the cardiac or renal variant., ${ }^{2,3}$ Whether different expression is related to residual enzyme activity

*Correspondence: F Verovnik, General Hospital Slovenj Gradec, Gosposvetska 1, SI-2380 Slovenj Gradec, Slovenia. Tel: + 38628842 393; Fax: + 38628842 393; E-mail: franc.verovnik@sb-sg.si Received 9 November 2003; revised 21 January 2004; accepted 30 January 2004 and subsequently mutation specific, or because of the other factors remains unclear. Currently, over 200 different mutations in the $\alpha$-Gal A gene have been documented and most are private (eg, family specific) mutations. This hampers genotype/phenotype correlations. ${ }^{4}$ We report the first Slovenian family with Fabry disease, consisting of 44 family members (see Figure 1). This family shows that despite a single mutation the clinical expression of renal disease in Fabry disease may be remarkably heterogeneous.

\footnotetext{
Methods

Subjects

Patients $(N=31)$ were seen at the General Hospital Slovenj Gradec in Slovenia. After obtaining informed consent EDTA anticoagulated blood was drawn for $\alpha$-Gal A activity analysis and DNA mutation analysis. Male patients with confirmed $\alpha$-Gal A deficiency $(N=7)$ underwent physical examination, routine laboratory tests, $24 \mathrm{~h}$ creatinine clearance, chest X-rays, ECG, echocardiography, ultrasonography of the abdominal organs, skin biopsy (if angiokeratoma were present) and ophthalmologic examination.
} 

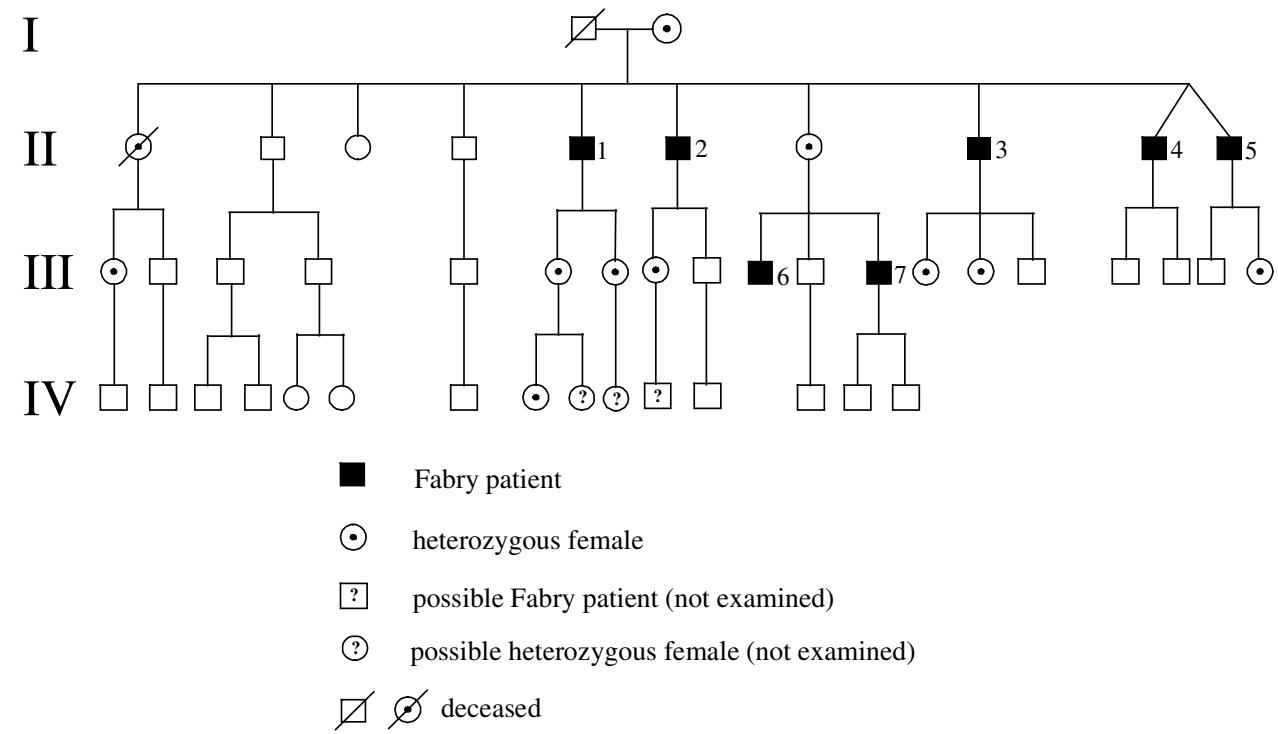

Figure 1 Pedigree of the family.

\section{Measurement of enzyme activity}

Blood was spun and plasma was transferred and stored at $-20^{\circ} \mathrm{C}$. Leucocytes were isolated following lysis of erythrocytes with ammonium chloride and stored at $-20^{\circ} \mathrm{C}$. The leucocytes-pellet was sonificated twice in $300 \mu \mathrm{l}$ water for $10 \mathrm{~s}$ and $\alpha$-Gal A activity was determined as described elsewhere. ${ }^{5}$ Results are expressed as $\mathrm{nmol} / \mathrm{mg}$ prot $/ \mathrm{h}$.

\section{Molecular analysis of the $\alpha$-Gal A gene}

Analysis of the $\alpha$-Gal A gene was performed by sequencing of the entire $\alpha$-Gal A gene in the proband, as described elsewhere. ${ }^{6}$ A mutation in exon 6 was identified, which resulted in an additional restriction site for the endonuclease FnU4H1. Subsequently, restriction analysis with Fnu4H1 was performed in all the other subjects. The product of a PCR compromising both exons 5 and 6 was digested with FnU4H1 and the result was run on an agarose gel. The number of DNA-fragments was interpreted as normal, hemizygote or heterozygote.

\section{Results}

\section{Enzyme analysis}

Seven males had reduced leucocyte $\alpha$-Gal activity, ranging from 0.5 to $1.4 \mathrm{nmoles} / \mathrm{h} / \mathrm{mg}$ prot (normal: $63-365 \mathrm{nmol} /$ $\mathrm{h} / \mathrm{mg}$ prot). The median age of these males was 47 years (range 28-58 years). Female carriers $(N=10)$ showed low $(N=7)$ to normal $(N=3)$ leucocyte $\alpha$-Gal A activity, ranging from 34.8 to $87.1 \mathrm{nmoles} / \mathrm{h} / \mathrm{mg}$ prot. The median age of carriers was 35 years (10-82 years).

\section{Mutation analysis}

In all male $\alpha$-Gal A-deficient patients, an $A$ to $G$ point mutation at position 10523 in exon 6 was identified, which resulted in an amino-acid change from asparagine to serine at position 272 (N272S). Heterozygosity was documented in 10 female patients.

\section{Clinical manifestations of male patients}

Symptoms are summarized in Table 1 . All the male patients had experienced neuropathic pains (acroparesthesias) during childhood and adolescence and they were still present in the two youngest patients (aged 28 and 33 years). Four patients had angiokeratoma. All suffered from hypohydrosis or anhydrosis, and reported heat intolerance. Cornea verticillata and tortuosity of retinal vessels were present in all.

Renal disease Three patients have renal failure: two on haemodialysis and one on peritoneal dialysis. The onset of renal failure was at the ages 40, 55 and 56 years, respectively. Moderate proteinuria (defined as $1-3.5 \mathrm{~g} \mathrm{pr} /$ $24 \mathrm{~h}$ ) was present in two other patients (aged 46 and 51 years), and mild (defined as $<1 \mathrm{~g} \mathrm{pr} / 24 \mathrm{~h}$ ) in two younger males (aged 28 and 33 years), but renal function was preserved. All of them were normotensive all their life. No confounding factors (smoking, body mass index) could be identified that could explain the differences in renal function.

Cardiac disease All the patients had similar ECG changes indicative of left ventricular hypertrophy (LVH). The two oldest patients (aged 57 and 58 years) suffered from atrial fibrillation. Echocardiographic studies demon- 
Table 1 Clinical symptoms and signs of Fabry disease in seven patients

\begin{tabular}{|c|c|c|c|c|c|c|c|c|c|}
\hline Pt & $\begin{array}{l}\text { Age } \\
\text { (year) }\end{array}$ & $\alpha-$ Gal $A$ & Angiokeratoma & Acroparesthesias & $\begin{array}{c}\text { Proteinuria } \\
(\mathrm{g} / \mathrm{L})\end{array}$ & $\begin{array}{l}\text { Creatinine } \\
\text { clearance } \\
\text { (ml/min) }\end{array}$ & $\begin{array}{c}\text { Left ventricular } \\
\text { hypertrophy }\end{array}$ & $\begin{array}{c}\text { Rhythm } \\
\text { distrurbances }\end{array}$ & $\begin{array}{c}\text { Clinically } \\
\text { apparent } \\
\text { stroke }\end{array}$ \\
\hline 1 & 58 & 0,5 & - & + & Dialysis & $\begin{array}{l}\text { Dialysis } \\
\text { (age } 56 \text { ) }\end{array}$ & ++ & Atrial fibrillation & + \\
\hline 2 & 57 & 0,8 & +++ & + & Dialysis & $\begin{array}{l}\text { Dialysis } \\
\text { (age 55) }\end{array}$ & & Atrial fibrillation & + \\
\hline 3 & 51 & 0,8 & - & + & 1,89 & 114 & ++ & - & - \\
\hline 4 & 46 & 0,8 & ++ & + & Dialysis & $\begin{array}{l}\text { Dialysis } \\
\text { (age } 40 \text { ) }\end{array}$ & ++ & - & - \\
\hline 5 & 46 & 0,8 & + & + & 1,29 & 98 & + & - & - \\
\hline 6 & 33 & 1,4 & + & +++ & 0.18 & 84 & + & - & - \\
\hline 7 & 28 & 0,5 & - & ++ & 0.87 & 92 & ++ & - & - \\
\hline
\end{tabular}

$\alpha$-Gal A: $\alpha$-galactosidase A activity in leuckocytes (normal: $63-365 \mathrm{nmol} / \mathrm{h} / \mathrm{mg}$ prot). + , mild; ++, moderate; +++, severe

strated various stages of concentric LVH increasing with age and with normal cavities dimensions. Interventricular septum thickness was increased (from 14 to $22 \mathrm{~mm}$, depending on age), with normal ejection fraction. Exertional angina was present in the oldest three males aged 51, 57 and 58 years, of which the latter two patients had a myocardial infarction requiring a coronary angioplasty (PTCA) procedure in one. None of them had signs of overt heart failure.

Other symptoms All males suffered from gastrointestinal complaints, mainly compromising of episodic diarrhoea, abdominal pain or nausea. Cerebrovascular accidents had occurred in the two oldest males, resulting in vertigo and gait instability. One patient demonstrated basilar artery ectasy on CT scan and cerebral angiography, as described by others. ${ }^{7,8}$

\section{Female carriers}

In the 10 female carriers, symptoms were much milder, a finding confirmed by others. ${ }^{9}$ None of them suffered from renal failure, severe cardiac disease or had experienced a stroke. Acroparesthesias were present in four patients, two had angiokeratoma and six complained of hypohydrosis. Cornea verticillata was found in five, as was mild proteinuria. Only one patient had a slight increase in creatinine value. One patient had cardiac hypertrophy noted on ECG, which was confirmed by echocardiography.

\section{Discussion}

In the present family of seven male and 10 female members, Fabry disease was diagnosed by the identification of a mutation in exon 6 (N272S) mutation, which, to our knowledge, has not been described previously.

Whereas leucocyte $\alpha$-Gal A activity was virtually absent in hemizygous patients, three out of 10 heterozygotes (33\%) had normal values, which is in line with other reports. ${ }^{10,11}$ This result once more emphasizes the need for
$\alpha$-Gal A gene analysis for reliable heterozygote detection. Even though this mutation causes classical Fabry disease, there is considerable variety of clinical manifestations among the seven hemizygotes. Only to some extent did disease severity correlate with advanced age. Whereas acroparesthesias, cornea verticillata and dyshydrosis were present in all patients, only four patients showed angiokeratoma and only one of them had a widely extended skin involvement.

The variability in renal disease is the most prominent, especially in twin-brothers. In three patients dialysis was needed at ages 56, 55 and 40 years (the first of the twinbrothers), respectively, whereas four other patients had normal creatinine clearance at ages $28,33,41$ and 40 years (the other twin-brother) and preserved normal renal function. The natural history in the three patients on dialysis shows that once creatinine levels are above $150 \mu \mathrm{mol} / \mathrm{l}$, progression to renal failure is rapid. Therefore, routine determination of renal function by means of $24 \mathrm{~h}$ urine creatinine clearance or, preferably, true GFR measurements by Cr-EDTA or inulin clearance is important to detect early loss of renal function.

It is well-known from various reports that different types of mutations in Fabry disease patients have a poor genotype-phenotype correlation ${ }^{12}$ and that a single mutation in one family may cause different phenotypes. ${ }^{13}$ In addition, mutations previously found in mild cases are also seen in severely diseased patients. ${ }^{14}$ This suggests the presence of other interacting factors that might influence the clinical expression, such as the influence of modifier genes and other genetic or environmental factors. Studying large families with Fabry disease may give an insight into such factors. Identification of factors that have an impact on the course of Fabry disease is of great value as it may aid in the decision to start the treatment early, before the onset of symptoms. In studies with rh- $\alpha \mathrm{Gal} \mathrm{A}$, it has been shown that renal function is not likely to improve following enzyme supplementation therapy. ${ }^{15}$ Since the natural history suggests that renal failure may develop rapidly 
once creatinine levels are above $150 \mu \mathrm{mol} / \mathrm{l}$, it may be vital to start treatment before the loss of renal function has reached this level.

In conclusion, although in the presented family, the N272S mutation of the $\alpha$-Gal A gene was correlated with the classical phenotype of Fabry disease, there was considerable difference in clinical expression between the family members. Further studies of families with Fabry disease may give an insight into other factors that influence the phenotype of this disorder.

\section{Acknowledgements}

We thank Dr. CEM Hollak for her critical review of the manuscript.

\section{References}

1 Desnick RJ, Ioannou YA, Eng ME: $\alpha$-Galactosidase A deficiency: Fabry disease; in: Scriver CR, Beaudet AL, Sly WS, Valle D (eds). The metabolic and molecular bases of inherited disease. New York: McGraw-Hill, 2001, Vol 3: 8th edn. pp 3733-3774.

2 Nakao S, Kodama C, Takenaka T et al: Fabry disease: detection of undiagnosed hemodialysis patients and identification of a "renal variant" phenotype. Kidney Int 2003; 64: 801-807.

3 von Scheidt W, Eng CM, Fitzmaurice TF et al: An atypical variant of Fabry's disease with manifestations confined to the myocardium. N Engl J Med 1991; 324: 395-399.

4 Eng CM, Desnick RJ: Molecular basis of Fabry disease: mutations and polymorphisms in the human alpha-galactosidase A gene. Hum Mutat 1994; 3: 103-111.

5 Blom D, Speijer D, Linthorst GE, Donker-Koopman WG, Strijland A, Aerts JM: Recombinant enzyme therapy for Fabry disease
Absence of editing of human $\alpha$-Galactosidase A mRNA. Am J Hum Genet. 2003; 72: 23-31.

6 Linthorst GE, Hollak CEM, Korevaar JC, van Manen JG, Aerts JMFG, Boeschoten EW: \\{alpha $\backslash\}$-Galactosidase A deficiency in Dutch patients on dialysis: a critical appraisal of screening for Fabry disease. Nephrol Dial Transplant 2003; 18 (8): 1581-1584.

7 Mitsias P, Levine SR: Cerebrovascular complications of Fabry's disease. Ann Neurol 1996; 40 (1): 8-17.

8 Nishizaki T, Tamaki N, Takeda N, Shirakuni T, Kondoh T, Matsumoto S: Dolichoectatic basilar artery: a review of 23 cases. Stroke 1986; 17 (6): 1277-1281.

9 Whybra C, Wendrich K, Ries M, Gal A, Beck M: Clinical manifestation in female Fabry disease patients. Contrib Nephrol 2001; 136: $245-250$.

10 Sheth KJ, Good TA, Murphy JV: Heterozygote detection in Fabry disease utilizing multiple enzyme activities. Am J Med Genet 1981; 10: $141-146$

11 Spence MW, Goldbloom AL, Burgess JK et al: Heterozygote detection in angiokeratoma corporis diffusum (Anderson-Fabry disease). Studies on plasma, leucocytes, and hair follicles. J Med Genet 1977; 14: 91-99.

12 Eng CM, Resnick-Silverman LA, Niehaus DJ, Astrin KH, Desnick RJ: Nature frequency of mutations in the alpha-galactosidase A gene that cause Fabry disease. Am J Hum Genet 1993; 53: 11861197.

13 Tager JM, Hamers MN, Schram AW et al: An appraisal of human trials in enzyme replacement therapy of genetic diseases. Birth Defects Orig Artic Ser 1980; 1 (1): 343-359.

14 Ashton-Prolla P, Tong B, Shabbeer J, Astrin KH, Eng CM, Desnick RJ: Fabry disease: twenty-two novel mutations in the alphagalactosidase A gene genotype/phenotype correlations in severely mildly affected hemizygotes heterozygotes. J Invest Med 2000; 48: 227-235.

15 Eng CM, Guffon N, Wilcox WR et al: Safety efficacy of recombinant human $\alpha$-galactosidase A replacement therapy in Fabry's disease. N Engl J Med 2001; 345: 9-16. 